\title{
CAPÍTULO 27: VARIABILIDADE ESPACIAL E TEMPORAL DA RESISTÊNCIA DO SOLO À PENETRAÇÃO NA REGIÃO DO VALE DO IVINHEMA/MS
}

\section{CHAPTER 27: SPATIAL AND TEMPORAL VARIABILITY OF SOIL RESISTANCE TO PENETRATION IN THE REGION OF IVINHEMA VALLEY / MS}

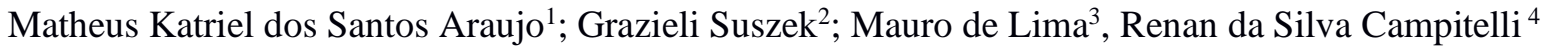

\begin{abstract}
Resumo
O estudo qualidade física do solo através da resistência do solo a penetração é uma boa forma de se verificar a eficiência de diferentes sistemas de manejo, e com isso, as suas implicações na qualidade física do solo, refletindo diretamente no desenvolvimento radicular da planta. Desta forma esse trabalho teve por objetivo avaliar a variabilidade espacial e temporal da compactação do solo em área agrícola na região do vale do Ivinhema-MS. Esse trabalho foi desenvolvido em área experimental pertencente ao Instituto Federal de Mato Grosso do Sul campus de Nova Andradina/MS. Na área experimental, foram implantadas as seguintes culturas, Soja (2017/2018) e Brachiaria brizantha cv. Marandu (2018/2019). Para a realização do trabalho, foi elaborado um Grid regular com malha amostral de $15 \times 20 \mathrm{~m}$, totalizando 24 pontos amostrais. Em cada ponto amostral foi realizada uma avaliação de resistência a penetração, determinação da umidade gravimétrica do solo e altimetria. Os dados obtidos das análises foram submetidos à análise estatística descritiva, para elaboração dos mapas foi utilizado o Software ArcGIS usando interpolação por IQD. Foi possível identificar variabilidade na área experimental através da avaliação da resistência do solo a penetração e encontrar correlação significativa entre resistência e a umidade do solo.
\end{abstract}

Palavras-Chaves: Agricultura de Precisão, Compactação do solo, Umidade do solo, Física do solo.

\begin{abstract}
The study of physical soil quality through soil resistance to penetration is a good way to verify the efficiency of different management systems, and with this, its implications on the physical quality of the soil, directly reflecting on the root development of the plant. Thus, this work aimed to evaluate the spatial and temporal variability of soil compaction in an agricultural area in the Ivinhema-MS valley region. This work was developed in an experimental area belonging to the Federal Institute of Mato Grosso do Sul - campus of Nova Andradina / MS. In the experimental area, the following crops, Soja (2017/2018) and Brachiaria brizantha cv. Marandu (2018/2019). In order to carry out the work, a regular grid with a $15 \times 20 \mathrm{~m}$ sample grid was elaborated, totaling 24 sample points. At each sampling point, an assessment of resistance to penetration, determination of soil gravimetric moisture and altimetry were performed. The data obtained from the analyzes were submitted to descriptive statistical analysis, for the elaboration of the maps the ArcGIS Software was used using IQD interpolation. It was possible to identify variability in the experimental area through the assessment of soil resistance to penetration and to find a significant correlation between resistance and soil

\footnotetext{
${ }^{1}$ Bacharelado em Agronomia, Instituto Federal de educação, ciência e tecnologia de Mato grosso do sul, matheus.araujo@novaandradina.org

${ }^{2}$ Doutorado em Engenharia Agrícola, Instituto Federal de educação, ciência e tecnologia de Mato grosso do sul, grazieli.suszek@ifms.edu.br

${ }^{3}$ Graduação em Engenharia Agrícola, Instituto Federal de educação, ciência e tecnologia de Mato grosso do sul, mauro.lima@ifms.edu.br

${ }^{4}$ Tecnólogo em Produção de Grãos, Instituto Federal de educação, ciência e tecnologia de Mato grosso do sul, renan.campitelli159@gmail.com.br
} 
moisture.

Keywords: Precision agriculture, Soil compaction, Soil moisture, Soil physics.

\section{Introdução}

O estudo da resistência a penetração do solo é um indicativo sobre o manejo da qualidade física dos solos, visto que essa propriedade apresenta relação com diversos atributos do solo, tais como os indicadores do grau de compactação, como a densidade, porosidade, conteúdo de água e textura do solo (CANCIAN, 2015). Em solos cultivados, é de fundamental importância para escolha do sistema de preparo mais adequado ao crescimento e desenvolvimento das culturas (RIBON e TAVARES FILHO, 2008).

A compactação do solo pode ser um fator limitante para a produção agrícola, gerando impacto na reorganização das partículas e agregados, o que por sua vez limita a adsorção, absorção de nutrientes, infiltração e redistribuição de água e trocas gasosa, afetando a produtividade dos cultivos (MORAES et al, 2020).

De acordo com FLOWERS \& LAL (1998), a principal causa da compactação em solos agrícolas é o tráfego de máquinas em operações de preparo do solo, semeadura, tratos culturais e colheita. Desta forma deve-se utilizar formas alternativas para a descompactação do solo sem causar grande impacto em sua estruturação.

Uma forma alternativa promissora é a descompactação biológica sem a degradação do solo com o uso de forrageiras e leguminosas capazes de ultrapassarem as camadas de compactação com seus sistemas radiculares vigorosos (RETKA, 2018), visto que após a decomposição das raízes obtém-se melhores condições do solo, por formarem bioporos no solo aumentando aspectos como a disponibilidade hídrica favorecendo a recuperação do solo (SANTOS et al, 2014).

Segundo Cancian (2015), a realização de avaliações da qualidade física do solo através da resistência do solo a penetração é uma boa forma de se verificar a eficiência de diferentes sistemas de manejo, e com isso, as suas implicações na qualidade física do solo, refletindo diretamente no desenvolvimento radicular da planta.

Desta forma, a análise da correlação entre os atributos do solo e a resistência a penetração poderia revelar dados importantes referentes aos futuros manejos desta área, possibilitando que possíveis intervenções possam ser realizadas com a finalidade de potencializar maiores produtividades e a obtenção de áreas mais homogêneas.

Para Bernardi et al. (2014) o conhecimento da variabilidade da produção é útil para qualquer cultura, sejam aquelas cultivadas em pequenas áreas ou em grandes extensões de terra. 
Desta forma é indispensável utilizar técnicas e métodos que indique ao produtor onde ocorre a variabilidade em sua propriedade agrícola, para que desta maneira possa se ter uma melhor produtividade. Desta forma o estudo da variabilidade dos atributos de solo possibilita aperfeiçoar o manejo em áreas agrícolas por meio de um gerenciamento que leve em consideração informações pontuais de solo e das culturas (AMADO, LEMAINSKI e SCHENATO, 2009).

Este trabalho teve por objetivo avaliar a variabilidade espacial e temporal da compactação do solo em área agrícola na região do vale do Ivinhema-MS.

\section{Material e Métodos}

A área experimental pertencente ao Instituto Federal de Mato Grosso do Sul- Fazenda Santa Bárbara, está localizada no município de Nova Andradina Estado do Mato Grosso do Sul, situada em $-22^{\circ} 08^{\prime} 22,65^{\prime}$ ' S e a $-53^{\circ} 46^{\prime} 89,60^{\prime}$ 'W (Figura 01), o clima da região é classificado, segundo Köeppen, como tropical subtropical úmido e mesotérmico, com índices pluviométricos superiores a $1100 \mathrm{~mm}$ anuais, possuindo altitude média de $357 \mathrm{~m}$, o solo da área é caracterizado como Latossolo Vermelho de textura arenosa conforme Santos et al. (2018), solo da área é composto por $82,68 \%$ de areia $2,6 \%$ de silte e $14,72 \%$ de argila.

Figura 1: Localização do experimento em Nova Andradina/MS.

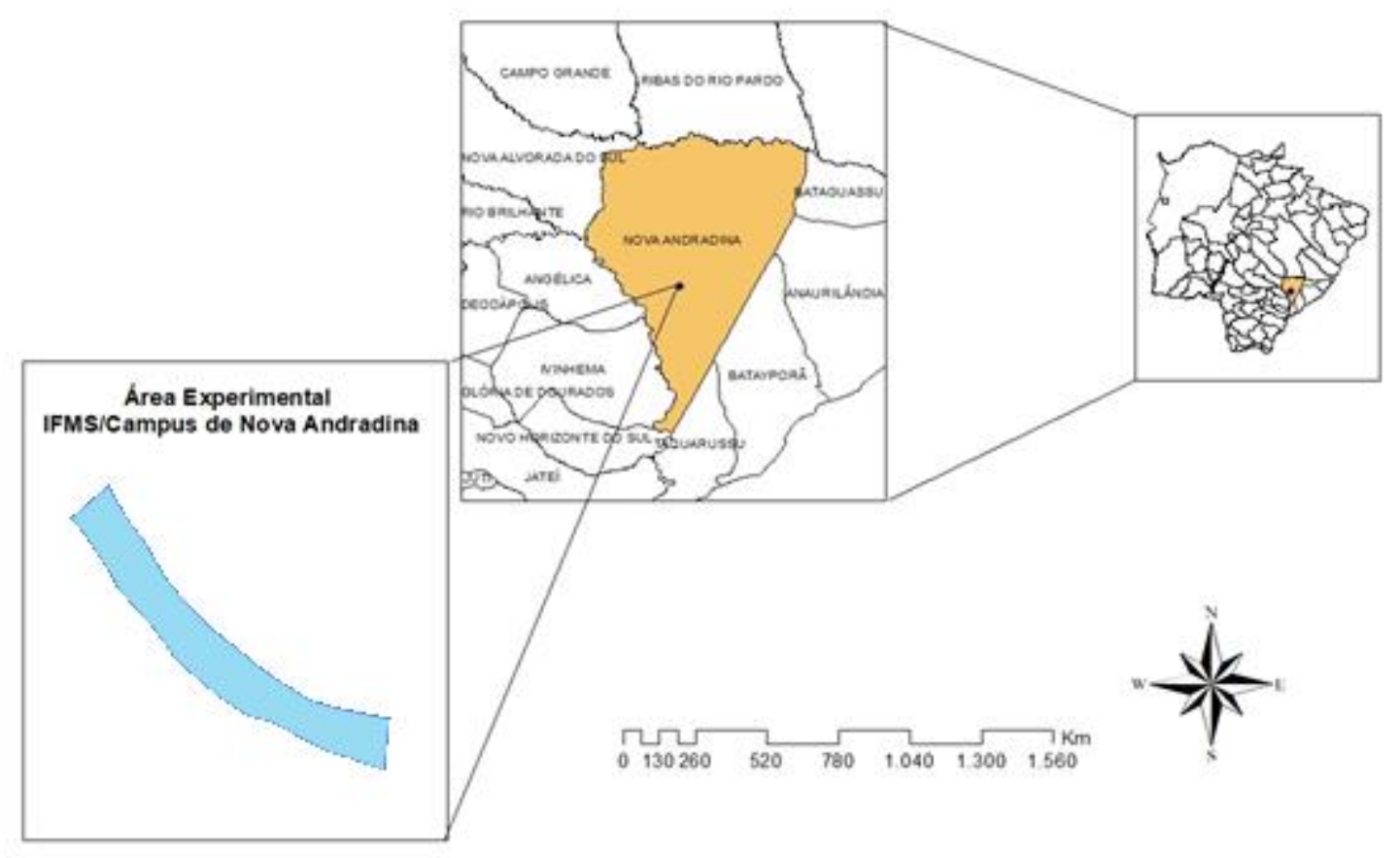

Fonte: Própria (2020). 
Durante o desenvolvimento do trabalho na área experimental, foram implantadas as seguintes culturas, Soja (2017/2018) e Brachiaria brizantha cv. Marandu (2018/2019). Para a realização do trabalho, foi elaborado um Grid regular com dimensão de malha amostral de $15 \times 20 \mathrm{~m}$, onde foram escolhidos 24 pontos amostrais (Figura 02), georreferenciados utilizandose GPS 76CSx da Garmin. Em cada ponto amostral foi realizada avaliação da resistência do solo a penetração e coleta de solo para determinação da umidade, nos meses de março/2018, abril/2019 e outubro/2019.

Figura 2: Distribuição dos pontos amostrais na área na experimental.

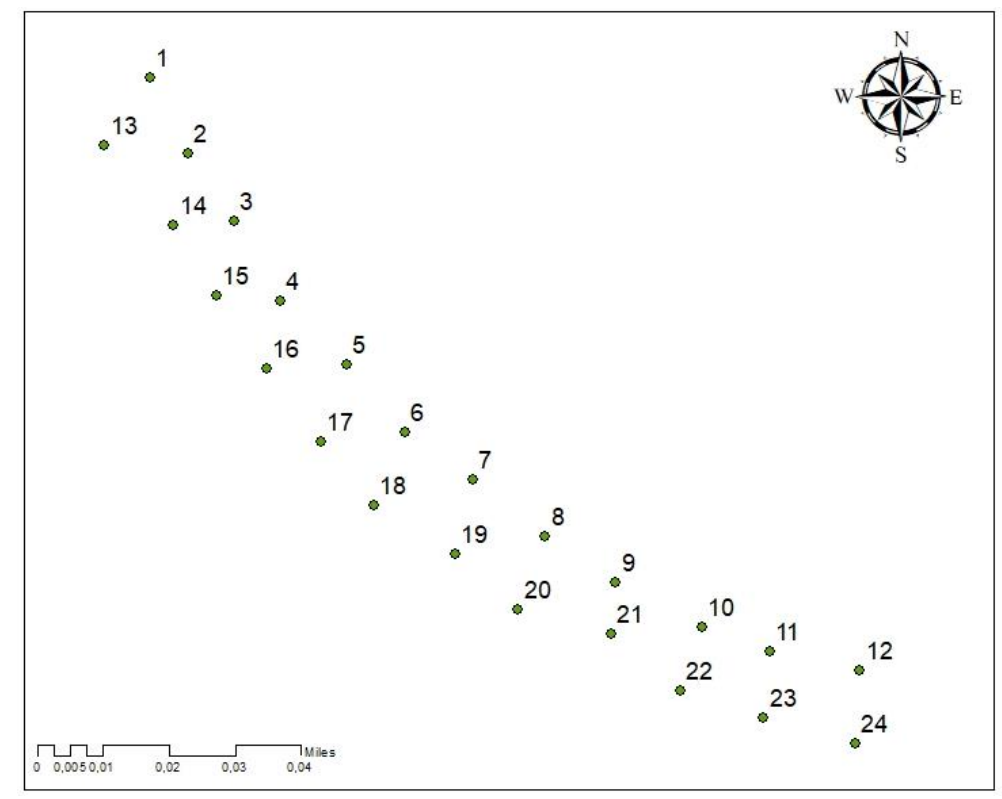

Fonte: Própria (2020).

A resistência mecânica à penetração realizada em março de 2018 foi obtida utilizando um penetrômetro de impacto, modelo IAA/Planalsucar-Stolf, com metodologia para coleta de dados sugerida por Stolf (1991), sendo utilizado para avaliação de 2018. Os resultados obtidos em impactos $\mathrm{dm}^{-1}$ foram convertidos em resistência dinâmica (MPa) por meio da equação 1 (Stolf, 1991). Para conversão da RP em kgf cm equação 1 pela constante 0,0981, dada por:

$\mathrm{RP}\left(\mathrm{Kgf} \mathrm{cm}^{-2}\right)=5,6+6,89 \mathrm{~N}\left(\right.$ impactos $\left.\mathrm{dm}^{-1}\right)$

Onde RP: resistência a penetração.

As avaliações de 2019, foi utilizado o penetrômetro eletrônico, modelo FALKER PenetroLOG - PLG1020, com aptidão eletrônica para aquisição de dados. Este penetrômetro foi configurado para registrar leituras a cada $0,01 \mathrm{~m}$ de incremento de profundidade, trabalhando em velocidade de penetração constante. Os dados referentes ao penetrômetro Falker foram extraídos da memória digital e analisados a uma profundidade máxima de 0,2 m. 
Para o processamento dos dados de resistência à penetração, foi utilizado o Software PenetroLOG. Em relação aos dados dos dois aparelhos utilizados os autores Vogel et al. (2017) e Lima, León e Silva (2013) relatam que os mesmos apresentam similaridade entre os dados.

Durante as avaliações de resistência do solo a penetração, também foram coletadas amostras de solo na profundidade de $0-20 \mathrm{~cm}$, para determinação da umidade através do método gravimétrico (Santos et al., 2018), assim as amostras foram coletadas utilizando trado holandês (Figura 03), posteriormente as amostras foram envolvidas em papel alumínio, e levadas ao laboratório de solos e nutrição de plantas do IFMS, campus Nova Andradina-MS, para pesagem e secagem em estufa a $105^{\circ} \mathrm{C}$ por 24 horas (Figura 04).

Figura 3: Coleta das amostras de solo, utilizando trado holandês.

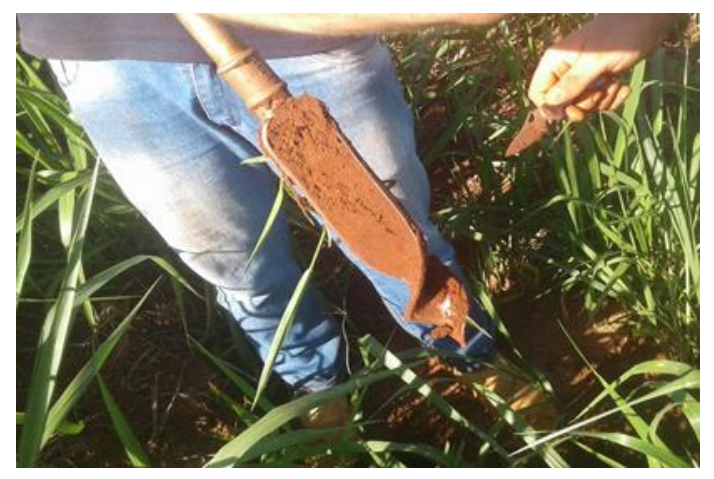

Fonte: Própria (2019).

Figura 4: Amostras de solo em estufa para realização da secagem.

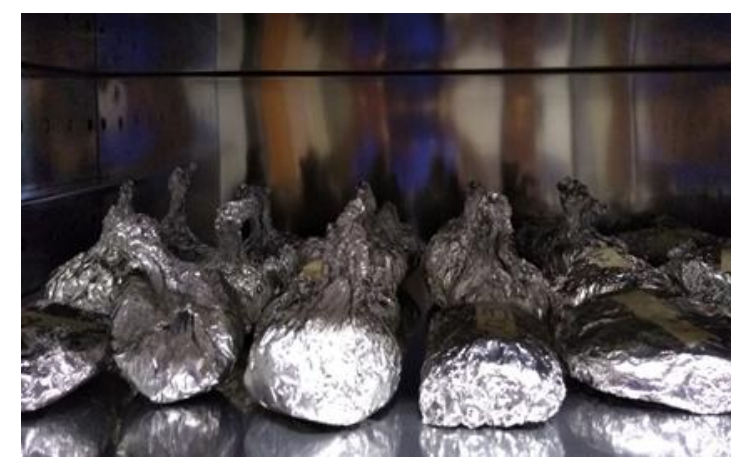

Fonte: Própria (2019).

Posteriormente os dados foram submetidos à análise exploratória, para obtenção das medidas de posição (média e mediana), medida de dispersão (desvio-padrão) e medidas de forma da distribuição (coeficiente de variação), avaliado de acordo com (Gomes, 2000), sendo também realizadas análises de correlação de Pearson e teste de normalidade, verificada através dos testes de Anderson Darling e Kolmogorov Smirnov (5\% de significância).

Para elaboração dos mapas temáticos da área experimental foi utilizado o software ArcGIS, onde os dados foram interpolados utilizando o interpolador inverso do quadrado da 
distância (IQD), interpolador determinístico univariado de médias ponderadas, ou seja, quanto mais distante um ponto observado estiver do estimado, menor será sua influência sobre o valor de inferência. Este método é considerado de acurácia satisfatória quando comparado a krigagem, podendo, em alguns casos, apresentar resultados semelhantes (SOUZA et al., 2010). Além disso a similaridade dos mapas temáticos construídos a partir dos dados coletados foi avaliada por meio de análise visual dos mapas.

\section{Resultados e Discussão}

$\mathrm{Na}$ Tabela 01 são apresentados os valores obtidos na coleta dos dados, referente à estatística descritiva das variáveis estudadas na camada de 0-0,20 m do solo. De acordo com a média da resistência do solo a penetração apresentou valores acima do estabelecido para o desenvolvimento radicular das plantas apenas na primeira análise em 2018, segundo Canarache (1990) valores acima de 2,5 MPa começam a restringir o pleno crescimento das raízes da maioria das plantas. Já Bergamin et al. (2010), observou que valores acima de 0,64 MPa apresenta limitação ao desenvolvimento de raízes da cultura do milho.

Tabela 1- Análise estatística dos dados de resistência do solo (MPa) e teor de umidade (\%).

\begin{tabular}{|c|c|c|c|c|c|c|c|}
\hline & \multirow{3}{*}{ Altitude (m) } & \multicolumn{2}{|c|}{$1^{\mathrm{a}}$ Análise: } & \multicolumn{2}{|c|}{$2^{\mathrm{a}}$ Análise: } & \multicolumn{2}{|c|}{$3^{\mathrm{a}}$ Análise: } \\
\hline & & \multicolumn{2}{|c|}{ Março/2018 } & \multicolumn{2}{|c|}{ Abril/2019 } & \multicolumn{2}{|c|}{ Out./2019 } \\
\hline & & $\mathrm{R}(\mathrm{MPa})$ & $\mathrm{h}(\%)$ & $\mathrm{R}(\mathrm{MPa})$ & $\mathrm{h}(\%)$ & $\mathrm{R}(\mathrm{MPa})$ & $\mathrm{h}(\%)$ \\
\hline Média & 344,02 & 3,40 & 7,04 & 0,40 & 6,69 & 0,45 & 5,99 \\
\hline Mediana & 338,51 & 3,32 & 6,98 & 0,40 & 6,86 & 0,42 & 6,01 \\
\hline Máximo & 374,80 & 5,38 & 8,83 & 0,59 & 8,56 & 0,70 & 7,18 \\
\hline Mínimo & 331,06 & 1,94 & 5,90 & 0,21 & 3,32 & 0,20 & 4,21 \\
\hline D.P. & 11,89 & 0,82 & 0,68 & 0,08 & 1,02 & 0,12 & 0,63 \\
\hline C.V. & 3,46 & 24,12 & 9,72 & 20,05 & 15,30 & 26,80 & 10,55 \\
\hline Curtose & 0,62 & 0,31 & 0,70 & 1,22 & 4,72 & $-0,01$ & 1,43 \\
\hline Assimetria & 1,18 & 0,24 & 0,63 & 0,12 & $-1,59$ & 0,42 & $-0,60$ \\
\hline Normalidade & Não & Sim & Sim & Sim & Sim & Sim & Sim \\
\hline
\end{tabular}

* R - Resistencia do solo a penetração, h - Umidade do solo, D.P. - Desvio Padrão, C.V. - Coeficiente de variação, Out.- Outubro.

Fonte: Própria (2020).

Em conformidade com os resultados apresentados na Tabela 01, nota-se que no teste de normalidade das 3 análises de resistência do solo a penetração e de umidade do solo, mostraram distribuição normal, já a altitude da área experimental não apresentou distribuição normal. 
Resultado semelhante foi relatado por Silva et al (2004) e por Cancian (2015). Segundo Ivo e Filho (1997), a normalidade da distribuição dos dados é a premissa básica para aplicação da maioria dos testes de significância. Isso determina a necessidade de uma maior atenção a esta medida quando se comparam dados, isso indica também a validação do uso da média de tendência central de determinado conjunto de dados (CANCIAN, 2015).

$\mathrm{Na}$ Tabela 01 pode-se observar também que a altitude, a $1^{\circ}$ análise de umidade e a Resistencia do solo a penetração apresentaram coeficiente de assimetria positivos variando de 1,18 a 0,12 , já os demais atributos apresentaram coeficiente de assimetria negativos com valores entre -0,60 a -1,59. Além disso, observando-se o coeficiente de curtose percebe-se que somente a $3^{\circ}$ análise de resistência do solo a penetração mostrou-se negativo $(-0,01)$, porém os demais atributos avaliados apresentaram coeficiente de curtose positivo com valores variando entre 0,31 a 4,72. Resultado similar foi obtido por Oliveira et al. (2018).

De acordo com Dalchiavon et al. (2012) a variabilidade de um atributo pode ser classificada conforme a magnitude de seu coeficiente de variação $(\mathrm{CV})$ como baixo $(\mathrm{CV}<$ $10 \%)$, médio $(10 \%<\mathrm{CV}<20 \%)$, alto $(20 \%<\mathrm{CV}<30 \%)$ e muito alto (CV > 30\%).

Com base nos resultados apresentados na Tabela 01, pode-se observar que as 3 avaliações de resistência do solo a penetração apresentaram Coeficiente de Variação (CV) alto, indicando que esses dados apresentam comportamento heterogêneo na área experimental. Por outro lado o teor de umidade do solo na $1^{\circ}$ análise e a altitude apresentaram coeficiente de variação baixo, e as demais análises apresentaram valores considerados médios, desta forma na $1^{\circ}$ analise a umidade do solo e a altitude demostram distribuição homogênea na área avaliada e nas demais análises o comportamento mostra-se heterogêneo. Resultados semelhantes foram relatados por Campos et al. (2012) e por Souza et al. (2006). Segundo relata Silva et al. (2004) na superfície e até a profundidade de $12 \mathrm{~cm}$, o solo sofre os maiores efeitos do tráfego de máquinas, da atividade biológica e de ciclos de umedecimento e secagem que provocam grande variabilidade e dispersão dos valores de RP.

Nos valores de máximo e mínimo das análises de resistência a penetração do solo apresentados na Tabela 01 , nota-se que na $1^{\circ}$ avaliação houve maiores valores de RP, isso deve ao manejo realizado na cultura anterior. De acordo Richart et al. (2005), algumas práticas de manejo do solo e das culturas provocam alterações nas propriedades físicas do solo, as quais podem ser permanentes ou temporárias. Já nas demais análises de resistência do solo a penetração constatou-se redução nos valores máximo e mínimo, isso ocorre pelo fato do uso de gramineas do gênero Brachiaria favorecer na descompactação biológica do solo (NETO et al., 2015). 
De acordo com a Tabela 02, pode-se observar a correlação de Pearson (r) entre a Resistencia do solo a penetração e a umidade do solo. Conforme Filho e Júnior (2009) uma correlação perfeita (-1 ou 1) indica que a contagem de uma variável pode ser determinada exatamente ao se saber a contagem da outra, no outro oposto, uma correlação de valor zero indica que não há relação linear entre as variáveis. Para interpretação das análises do coeficiente de correlação utilizou-se a proposta estabelecida por Dancey e Reidy (2006).

Tabela 2. Coeficiente de correlação de Pearson dos atributos avaliados.

\begin{tabular}{lcccccc}
\hline & \multicolumn{2}{c}{$1^{\circ}$ Análise } & \multicolumn{2}{c}{$2^{\circ}$ Análise } & \multicolumn{2}{c}{$3^{\circ}$ Análise } \\
\cline { 2 - 8 } & $\mathrm{R}(\mathrm{Mpa})$ & $\mathrm{h}(\%)$ & $\mathrm{R}(\mathrm{Mpa})$ & $\mathrm{h}(\%)$ & $\mathrm{R}(\mathrm{Mpa})$ & $\mathrm{h}(\%)$ \\
\hline Corr. Alt. & $-0,24$ & $\underline{0,53}$ & $-0,14$ & 0,13 & 0,07 & $-0,10$ \\
\hline Correlação & & 0,23 & & & 0,11 & \multicolumn{2}{c}{$\underline{0,31}$} &
\end{tabular}

$* \geq 0,60$ ou $\mathrm{r} \geq-0,60$ (Correlação Forte - Em negrito); $0,30 \leq \mathrm{r}<0,60$ ou $-0,60<\mathrm{r} \leq-0,30$ (Correlação Moderada - Em itálico e sublinhado); -0,30 < r < 0,30 (Correlação Fraca - Fonte normal) (Dancey e Reidy, 2006). R Resistencia do solo a penetração, h - Umidade do solo, Corr. Alt. - Correlação com Altitude.

Fonte: Própria (2020).

Conforme demonstra na Tabela 02, pode-se observar que houve correlação moderada $(0,30 \leq \mathrm{r}<0,60$ ou $-0,60<\mathrm{r} \leq-0,30)$ entre a resistência do solo a penetração e a umidade do solo na $3^{\circ}$ análise, já nas demais análises ocorreu correlação fraca entre os atributos avaliados, resultado semelhante foi relatado por Carvalho et al. (2006). Segundo Beltrame et al. (1981), a umidade pode alterar a coesão entre as partículas do solo. Já para Silveira et al. (2010), quando o solo está seco ou apresenta baixo conteúdo de água, suas partículas apresentam-se mais próximas e difíceis de serem separadas por qualquer força externa. Conforme relata Dedecek e Gava (2005), os solos arenosos possuem elevada macroporosidade, sua compactação tem que ser extremamente alta para haver redução drástica dessa porosidade. Já os solos argilosos, principalmente quando com umidade acima da capacidade de campo, tendem a ser compactados facilmente, diminuindo sua porosidade e podendo formar camadas compactadas.

$\mathrm{Na}$ Tabela 02 nota-se também que houve correlação moderada entre a $1^{\circ}$ analise de umidade do solo e a altitude da área experimental, esse resultado também foi relatado por Ribeiro (2010). Segundo Ferreira et al. (2010) quando se tem baixa declividade da superfície do solo tem-se, também, escoamento com baixa velocidade e, consequentemente, a capacidade de transporte fica limitada à vazão de escoamento.

Nas Figuras 05, 06 e 07 são apresentados os mapas de resistência a penetração e umidade do solo, para a $1^{\mathrm{a}}, 2^{\mathrm{a}}$ e $3^{\mathrm{a}}$ análises respectivamente. As escalas dos mapas foram padronizadas na divisão por quartis do ArcGIS, tendo por objetivo padronizar os mapas e com 
isso conseguir realizar a comparação visual, percebeu-se que todos os mapas apresentaram variabilidade espacial.

Figura 5: Mapas de resistência a penetração e umidade do solo resultantes da $1^{\circ}$ análise (Março/2018).

Mapa de resistência do solo a penetração

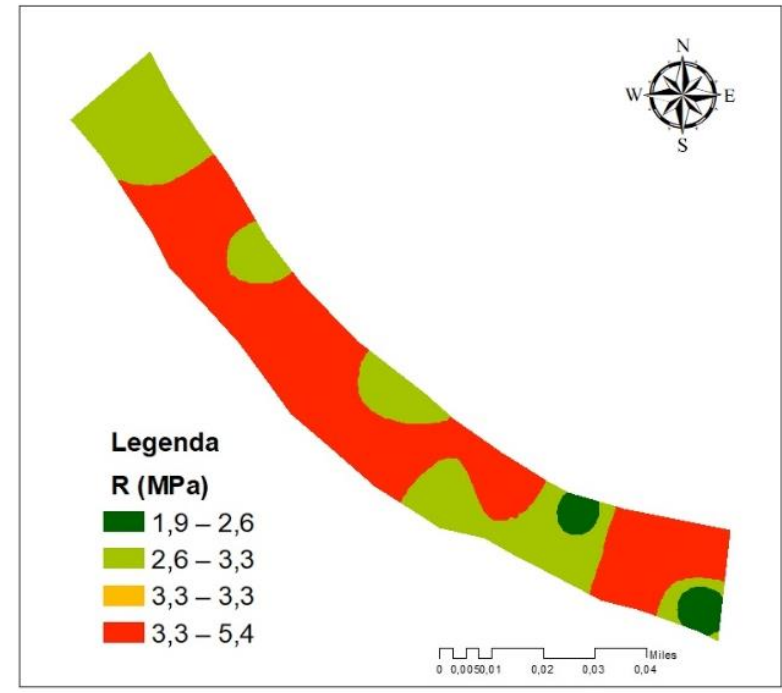

Mapa do teor de umidade do solo

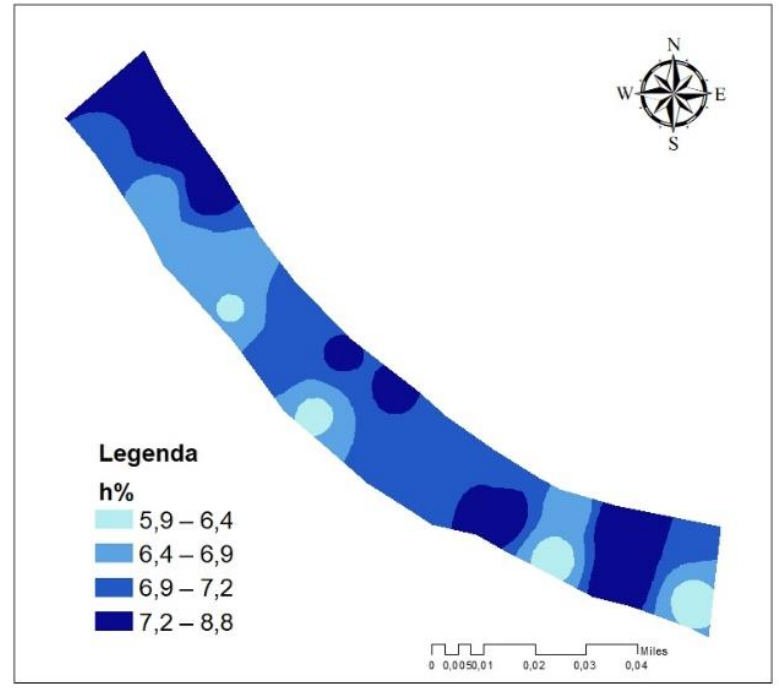

Fonte: Própria (2020).

De acordo com a Figura 05 não foi possível observar influência da umidade na resistência do solo a penetração. Além disso no mapa de resistência a penetração, percebe-se que na região central da área houve predominância de valores altos de resistência do solo a penetração, já no sentido noroeste os valores tendem a diminuir, o mesmo ocorre na região sudeste do mapa. De acordo com Barber (1994), os valores de resistência do solo à penetração a partir de 2,0 a 3,0 MPa dificultam o desenvolvimento radicular de culturas como a soja, causando deficiência de aeração no solo e menor drenagem interna. Segundo Cancian (2015), altos valores de resistência do solo a penetração são influenciados pelo manejo realizado na área agrícola.

Na Figura 06 observou-se variabilidade espacial nos dois mapas, porém também não houve correlação visual entre os mapas. O mapa de resistência do solo a penetração, apresentou os valores mais altos predominante nas regiões nordeste e sudeste do mapa, ja na região central do mapa ocorre predominância de valores que variam de médio a baixa resistência.

Além disso, houve redução nos niveis de resistência do solo a penetração, isso ocorreu devido a influência da Brachiaria brizantha cv. Marandu na descompactação do solo. Resultado semelhante foi relatado por Calonego et al. (2011), o cultivo de braquiária em consórcio com o milho por dois anos consecutivos melhorou as condições estruturais do solo, com redução da resistência mecânica à penetração, e consequentemente, aumento do intervalo 
hídrico ótimo (IHO). De acordo com Razuk (2002), uma das características atribuídas às gramíneas e, em particular, a Brachiaria brizantha cv. Marandu é a abundante produção de raízes e capacidade de estruturação do solo. Essas propriedades têm papel importante na capacidade de armazenamento de água no solo, absorção de nutrientes, melhoria de características físicas e aumento no teor de matéria orgânica do solo.

Figura 6: Mapas de resistência a penetração e umidade do solo resultantes da $2^{\circ}$ análise (Abril/2019).

Mapa de resistência do solo a penetração

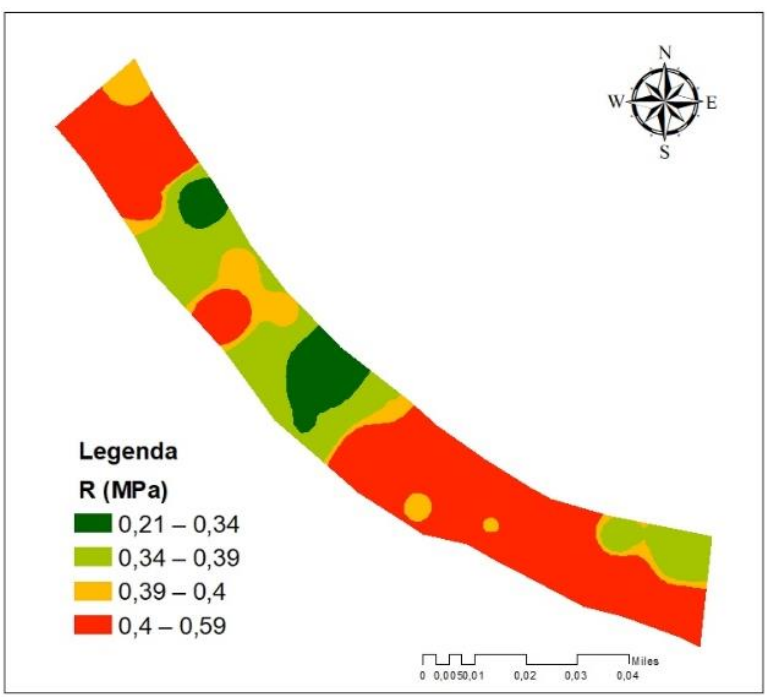

Mapa do teor de umidade do solo

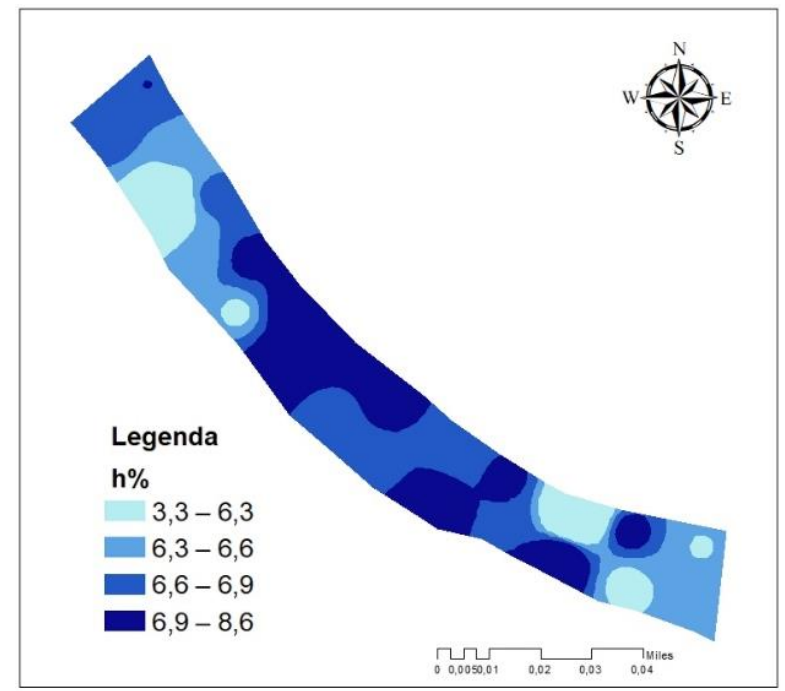

Fonte: Própria (2020).

Figura 7: Mapas de resistência a penetração e umidade do solo resultantes da $3^{\circ}$ análise (Outubro/2019).

Mapa de resistência do solo a penetração

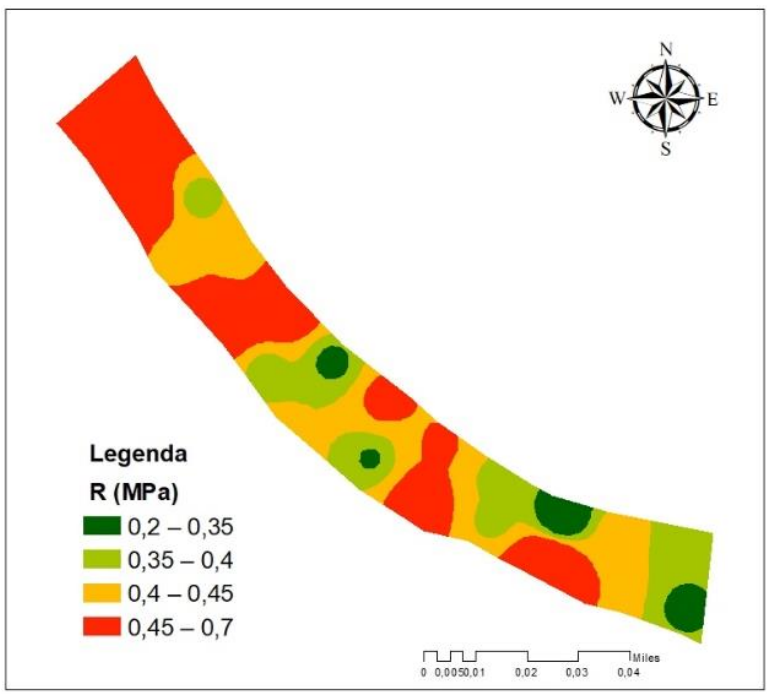

Mapa do teor de umidade do solo

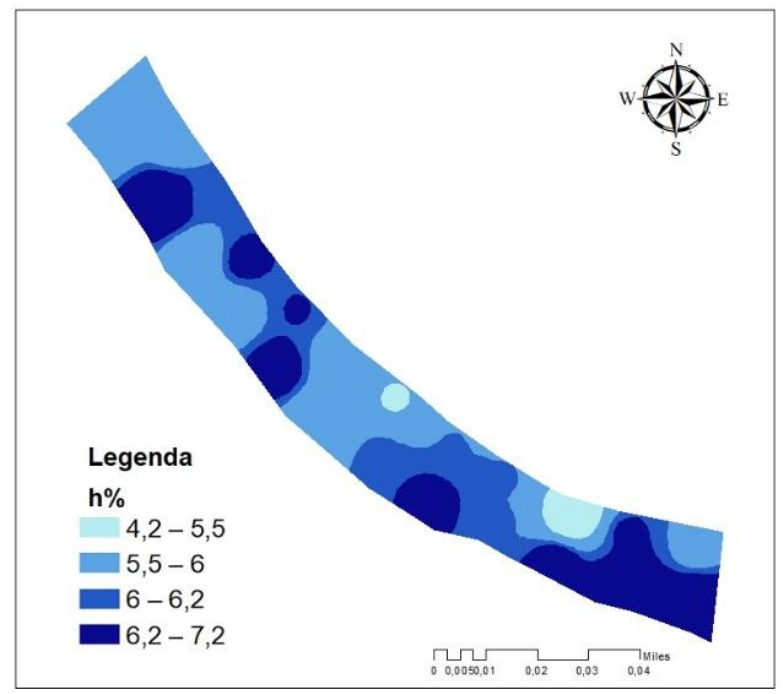

Fonte: Própria (2020). 
Também houve variabilidade espacial entre os atributos avaliados na $3^{\circ}$ análise (Figura 07), nota-se também a existência correlação entre umidade e resistência do solo a penetração em algumas regiões da área experimental. Desta forma observando-se o mapa de resistência do solo a penetração verifica-se que na região noroeste do mapa houve predominância de valores altos de resistência, onde esse fato pode ter sido influenciado pela baixa umidade naquela localidade. Já na região sudeste apresentou menores valores de resistência e maior teor de umidade do solo. De acordo com Cancian (2015), quando o teor de água aumenta, a resistência do solo a penetração tem seus valores diminuídos pela redução das forças de coesão que atuam entre as partículas de solo, o que ocasiona um aumento das forças de adesão, mudando a consistência de friável para plástica, e desta forma, alcançando valores limitantes ao crescimento de raízes em condições de baixo teor de umidade no solo.

De acordo com o resultado das 3 avaliações realizada na área experimental, pode-se notar que houve variabilidade espacial e temporal dos atributos avaliados, e que o estudo dessa variabilidade é indispensável para identificar áreas que necessitam de manejo e correção.

Figura 8: Mapa de altitude da área experimental.

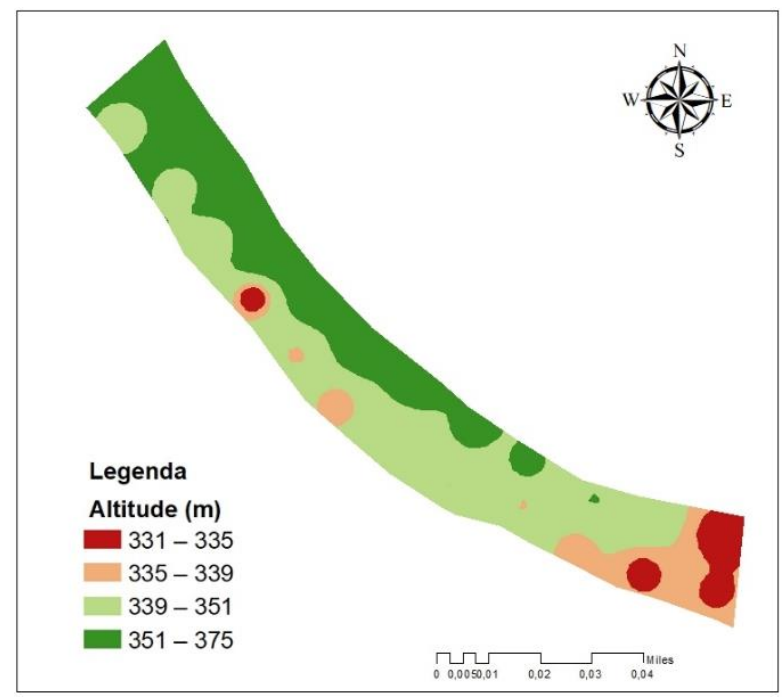

Fonte: Própria (2020).

Com base na Figura 08, nota-se que o mapa de altitude apresenta variabilidade na área experimental. Além disso, pode-se observar que na região nordeste do mapa foram obtidos maiores valores de altitude, já na região sudeste há predominância de menores níveis de elevação.

Realizando uma comparação visual entre o mapa de altitude e os mapas da $1^{\circ}$ análise (Figura 05) pode-se observar que na região de maiores altitude obteve-se predominância 
de maior umidade do solo, e predomínio de valores com menor resistência do solo a penetração. Já a comparação do mapa de altitude com mapas da $2^{\circ}$ análise (Figura 06) é possível observar que houve correlação entre os mapas, visto que na região sudeste da área apresentou menores valores de altitude, porém maiores valores de resistência do solo a penetração e menor teor de umidade do solo. Na comparação do mapa de altitude com os mapas da $3^{\circ}$ análise (Figura 07), observou-se que na região sudeste onde houve menores valores de altitude obteve-se predominância de maiores valores de umidade e menor resistência do solo a penetração.

\section{Conclusões}

Foi possível identificar variabilidade na área experimental através da avaliação espacial da resistência do solo a penetração e encontrar correlação significativa entre resistência do solo a penetração e a umidade do solo, e também entre a altitude e a umidade do solo.

A primeira avaliação da resistência do solo a penetração apresentou alto niveis de compactação, já nas demais avaliações ocorreu diminuição nos níveis de compactação do solo, devido a presença da Brachiaria brizantha cv. Marandu que influenciou na descompactação do solo.

O uso do mapeamento espacial e temporal dos atributos mostrou-se eficiente para identificação das áreas que necessitam de manejo diferenciado, mostrando que as técnicas de agricultura de precisão são ferramentas importantes para um tratamento adequado das áreas cultivadas.

\section{Referências}

AMADO, T. J. C.; PES, L. Z.; LEMAINSKI, C. L.; SCHENATO, R. B. Atributos químicos e físicos de Latossolos e sua relação com rendimentos de feijão e milho irrigados. Revista Brasileira de Ciência do Solo, Cap. 33, p. 831-843, 2009.

BERNARDI, A. C. C; Et al. Agricultura de precisão: resultados de um novo olhar. 1.ed. Brasília, DF: Embrapa, 2014.

BELTRAME, L.F.S.; GONDIN, L.A.P. \& TAYLOR, J.C. Estrutura e compactação na permeabilidade de solos do Rio Grande do Sul. Revista Bras. Ci. Solo, 5:145-149, 1981

CALONEGO, J. C.; BORGHI, E. \& CRUSCIOL, C. A. C. Intervalo hídrico ótimo e compactação do solo com cultivo consorciado de milho e braquiária. Revista Brasileira de Ciência do Solo, 35:2183-2190, 2011. 
CAMPOS, M.C.C.; Et al. Variabilidade espacial da resistência do solo à penetração e umidade em áreas cultivadas com mandioca na região de Humaitá, AM. Revista Agro@mbiente Online, v. 6, n. 1, p. 09-16, 2012.

CANCIAN, L. C. Variabilidade espacial da resistência a penetração, granulometria e umidade do solo. 2015. 59 f. Dissertação (Mestrado em Agronomia) - Curso de Pós-graduação em Agronomia, Universidade Federal de Santa Maria, RS. 2015.

CARVALHO, G.J.; Et al. Correlação da produtividade do feijão com a resistência à penetração do solo sob plantio direto. Revista Bras. Eng. Agríc. Ambiental, v.10, n.3, p.765-771, 2006.

DALCHIAVON, F.C.; Et al. Variabilidade espacial de atributos da fertilidade de um Latossolo Vermelho Distroférrico sob Sistema Plantio Direto. Revista Ciência Agronômica, v.43, p. 453-461, 2012.

DANCEY, C.; REIDY, J.. Estatística sem matemática para psicologia: usando SPSS para Windows. Porto Alegre: Artmed, 2006.

DEDECEK, R.A.; GAVA, J.L. Influência da compactação do solo na produtividade da rebrota de eucalipto. Rev. Árvore, Viçosa, vol. 29 n. 3, 2005.

FERREIRA, A.O.; Et al. Influência da declividade e de níveis de cobertura do solo no processo de erosão com chuva simulada. Revista Verde, Mossoró, v.5, n.5, p. 182 - 190. 2010.

FILHO, D.B.F.; JÚNIOR, J.A.S. Desvendando os Mistérios do Coeficiente de Correlação de Pearson (r). Revista Política Hoje, v. 18, n. 1, 2009.

FLOWERS, M.D., LAL, R. Axle load and tillage effects on soil physical properties and soybean grain yield on a mollic ochraqualf in northwest Ohio. Soil \& Tillage Research, Amsterdam, v.48, p.21-35, 1998.

GOMES, F.P. Curso de estatística experimental. $14^{\mathrm{a}}$ ed. Piracicaba, Degaspari. 200. 477p.

IVO, C.T.C.; FILHO, A.A.F. Estatística pesqueira: Aplicações em engenharia de pesca. Fortaleza, Tom Gráfica, 1997. 193 p.

LIMA, R. P.; LEÓN, M. J.; SILVA, A. R. Comparação entre dois penetrômetros na avaliação da resistência mecânica do solo à penetração. Rev. Ceres. Viçosa. v.6, n.4, p. 577-581, jul/ago, 2013.

MORAES, M.P. Et al. Correlação entre os penetrômetros manual e automático na determinação da resistência mecânica a penetração em latossolo vermelho. In: AMARAL, L.P. Congresso sul americano de Agricultura de Precisão e máquinas precisas. 5. ed. Não me toque: CESPOL, 2020. p 82 - 89.

NETO, J.F.; Et al. Biological soil loosening by grasses from genus Brachiaria in croplivestock Integration. Acta Scientiarum. Maringá, v. 37, n. 3, p. 375-383, 2015.

OLIVEIRA, D.G.; Et al. Correlação espacial de atributos físicos do solo e produtividade de tomate industrial. Revista Agro@mbiente On-line, v. 12, n. 1, p. 1-10, 2018. 
RAZUK, R.B. Avaliação do sistema radicular de acesso de Brachiaria brizantha e suas relações com atributos químicos e físicos do solo. 2002. 56 f. Dissertação (Mestrado) Universidade Federal de Mato Grosso do Sul, Dourados, 2002.

RIBON, A.A.; TAVARES FILHO, J. Estimativa da resistência mecânica à penetração de um Latossolo Vermelho sob cultura perene no norte do Estado do Paraná. Revista Brasileira de Ciência do Solo, v.32, p.1817-1825, 2008.

RIBEIRO, G.F.; Estudo dos fatores do meio físico que influenciam a capacidade de infiltração das águas da bacia hidrográfica vargens de caldas, Minas Gerais. 2010. 96 f. Dissertação (Mestrado) - Universidade estadual de Campinas, Campinas, 2010.

RICHART, A.; Et al. Compactação do solo: causas e efeitos. Ciências Agrárias, Londrina, v. 26, n. 3, p. 321-344, 2005.

RETKA, W.; Efeito da cultura do nabo forrageiro na descompactação do solo. 2018. 52 f. Trabalho de Conclusão de Curso (Graduação) - Universidade Tecnológica Federal do Paraná, Francisco Beltrão, 2018.

SANTOS, F.S., et al. A utilização de plantas de cobertura na recuperação de solos compactados. Acta Iguazu, Cascavel, v.3, n.3, p. 82-91, 2014.

SANTOS, H. G.; et al. Sistema Brasileiro de Classificação de Solos. 5. Brasília: 2018. 355 p.

SILVA, V.R.; Et al. Variabilidade espacial da resistência do solo à penetração em plantio direto. Ciência Rural, Santa Maria, v.34, n.2, p.399-406, 2004.

SILVEIRA, D.C.; Et al. Relação umidade versus resistência á penetração para um argissolo amarelo distrocoeso no recôncavo da Bahia. Revista Bras. Ci. Solo, v.34, p.659-667, 2010.

SOUZA, G.S. de et al. Krigagem ordinária e inverso do quadrado da distância aplicados na especialização de atributos químicos de um argissolo. Scientia Agraria, Curitiba, v. 11, n. 1, 2010. p $73-81$

SOUZA, Z.M.; Et al. Dependência espacial da resistência do solo à penetração e do teor de água do solo sob cultivo contínuo de cana-de-açúcar. Ciência Rural, Santa Maria, v.36, n.1, p.128-134, 2006.

STOLF, R. Teoria e teste experimental de fórmulas de transformação dos dados de penetrômetro de impacto em resistência do solo. Revista Bras. de Ciência do Solo, 15:229235, 1991.

VOGEL, Gabriel Felipe et AL. Avaliação dos penetrômetros de impacto e eletrônico na determinação da resistência mecânica à penetração do solo. Revista Scientia Agrária, Curitiba, v. 18, p.6-6, 29 set.2017. 